\title{
Effect of $\mathrm{SrBi}_{8} \mathrm{Ti}_{7} \mathrm{O}_{27}$ hetero-template on texture development in $\mathrm{Bi}_{4} \mathrm{Ti}_{3} \mathrm{O}_{12}$
}

\author{
Kenichi ONODERA and Toshio KIMURA ${ }^{\dagger}$ \\ Graduate School of Science and Technology, Keio University, 3-14-1 Hiyoshi, Kohoku-ku, Yokohama 223-8522, Japan
}

The effect of hetero-template grains on texture development in $\mathrm{Bi}_{4} \mathrm{Ti}_{3} \mathrm{O}_{12}$ (BiT) was examined. The hetero-template was $\mathrm{SrBi}_{8} \mathrm{Ti}_{7} \mathrm{O}_{27}\left(\mathrm{~S}_{0.5} \mathrm{BT}\right)$ grains with a large platelike shape. Texture developed in pure BiT made by solid-state reaction without template grains. The origin of texture development was attributed to the growth of small platelike grains with an aspect ratio of approximately 3 (homo-template) present in the BiT powder. The hetero-template grains added to the BiT powder promoted texture development, and the degree of the promotion was dependent on the amount of hetero-template. When the concentration of hetero-template was $1 \mathrm{vol} \%$, the hetero-template and homo-template acted as the origin of texture development. When the concentration was increased to $5 \mathrm{vol} \%$, the orientation of grains was almost only caused by the hetero-template. When the concentration was further increased to $10 \mathrm{vol} \%$, texture did not develop. $\mathrm{SrTiO}_{3}$ in the hetero-template dissolved in the $\mathrm{BiT}$ matrix grains, thus reducing the grain growth rate. These results indicate that grain growth is essential for texture development in BiT.

(2012 The Ceramic Society of Japan. All rights reserved.

Key-words : Texture development, Grain orientation, Templated grain growth, Hetero-template, Bismuth titanate

[Received December 6, 2011 ; Accepted March 26, 2012]

\section{Introduction}

Bismuth layer-structured ferroelectrics (BLSFs) are one of the candidates for lead-free piezoelectric ceramics for high-temperature use. ${ }^{1)}$ Because the crystal structure of BLSFs is highly anisotropic, the control of texture is important. ${ }^{2}$ The templated grain growth (TGG) process is one of the most convenient preparation methods for textured BLSF ceramics. ${ }^{3), 4)}$ In this method, a green compact is made from a mixture of large, platelike template grains and small, equiaxed matrix grains. The template grains are aligned in the green compact by methods such as tape-casting and extrusion. Dense, highly textured ceramics are obtained by sintering the green compact.

The piezoelectric properties are dependent not only on the composition but also on microstructure such as grain size. ${ }^{5), 6)}$ Understanding of the microstructure development in the compact made by the TGG process is necessary to obtain dense, highly textured ceramics with a controlled microstructure. In the preparation of ordinary ceramics, green compacts with a homogeneous structure are desirable. ${ }^{7}$ However, the green compacts used in the TGG process are nonuniform, i.e., they consist of oriented, anisometric grains and small, equiaxed grains with a random orientation. In BLSFs made by the TGG process, two mechanisms have been reported for the texture development. ${ }^{8)-10)}$ One is the growth of template grains at the expense of matrix grains and the other is the change in the shape and subsequent growth of matrix grains in the presence of template grains.

One of the authors has been studying the mechanism of texture development in BLSFs using homo- and hetero-templates. ${ }^{9)-12)}$ The use of a hetero-template has two advantages. First, it facilitates differentiation between template and matrix grains. Second, it allows us to examine the effect of only matrix-grain

$\dagger$ Corresponding author: T. Kimura; E-mail: kimura@applc. keio.ac.jp growth on the texture development, because template grains with a composition different from that of matrix grains do not grow. We have found that the amount of $\mathrm{SrBi}_{8} \mathrm{Ti}_{7} \mathrm{O}_{27}$ (abbreviated as $\mathrm{S}_{0.5} \mathrm{BT}$ ) hetero-template grains has a strong influence on the growth behavior of $\mathrm{Bi}_{4} \mathrm{Ti}_{3} \mathrm{O}_{12}(\mathrm{BiT})$ matrix grains. This paper reports the effect of $\mathrm{S}_{0.5} \mathrm{BT}$ concentration on the microstructure development.

\section{Experimental procedure}

2.1 Preparation of template and matrix powders Reagent-grade $\mathrm{SrCO}_{3}$ (Kojundo Chemical Laboratory Co. Ltd., Saitama, Japan), $\mathrm{Bi}_{2} \mathrm{O}_{3}$ (Kojundo Chemical Laboratory Co. Ltd., Saitama, Japan), and $\mathrm{TiO}_{2}$ (Ishihara Sangyo Kaisha Ltd., Osaka, Japan) were used as starting materials. Platelike $\mathrm{S}_{0.5} \mathrm{BT}$ powder for the template grains was prepared by molten salt synthesis. A stoichiometric mixture of $\mathrm{SrCO}_{3}, \mathrm{Bi}_{2} \mathrm{O}_{3}$, and $\mathrm{TiO}_{2}$ was heated at $1100^{\circ} \mathrm{C}$ for $1 \mathrm{~h}$ in the presence of $\mathrm{KCl}$ (Wako Pure Chemical Industries, Ltd., Osaka, Japan). The product was washed with deionized water. Figure 1 shows an SEM (scanning electron microscopy) photograph of the $\mathrm{S}_{0.5} \mathrm{BT}$ powder after the removal

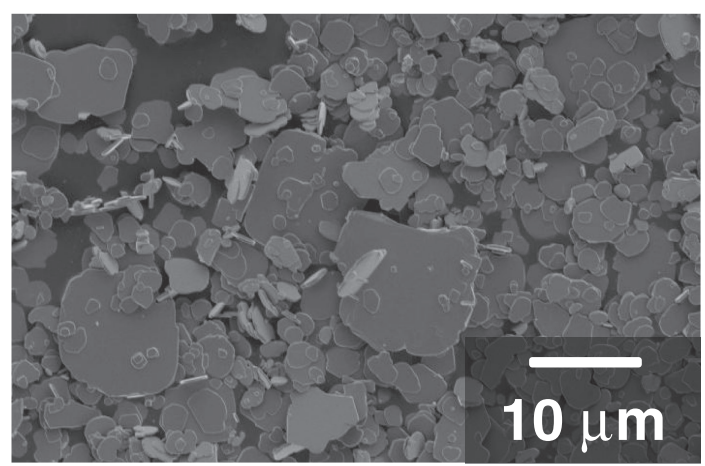

Fig. 1. Shape and size of $\mathrm{S}_{0.5} \mathrm{BT}$ platelike grains. 
of $\mathrm{KCl}$ by washing with deionized water. The obtained material was single-phase $\mathrm{S}_{0.5} \mathrm{BT}$ as confirmed by XRD (X-ray diffraction analysis). The grains had a platelike shape with a diameter between 2 and $12 \mu \mathrm{m}$ and a thickness of approximately $0.4 \mu \mathrm{m}$.

The BiT matrix powder was prepared by the conventional solid-state method. A stoichiometric mixture of $\mathrm{Bi}_{2} \mathrm{O}_{3}$ and $\mathrm{TiO}_{2}$ was calcined at $750^{\circ} \mathrm{C}$ for $1 \mathrm{~h}$. After calcination, the product powder was ball-milled first for $2 \mathrm{~h}$ using $\mathrm{ZrO}_{2}$ balls with a diameter of $15 \mathrm{~mm}$, and then for an additional $24 \mathrm{~h}$ using $\mathrm{ZrO}_{2}$ balls with a diameter of $2 \mathrm{~mm}$. The obtained material was singlephase BiT as confirmed by XRD. A majority of the grains were equiaxed in shape but some platelike grains with aspect ratios between 2 and 3 were present. Most of the grains were between 0.4 and $0.8 \mu \mathrm{m}$ in size.

In addition to the $\mathrm{S}_{0.5} \mathrm{BT}$ template and $\mathrm{BiT}$ matrix powders, $\mathrm{SrTiO}_{3}$ powder was prepared for an additional experiment. A stoichiometric mixture of $\mathrm{SrCO}_{3}$ and $\mathrm{TiO}_{2}$ was calcined at $1100^{\circ} \mathrm{C}$ for $3 \mathrm{~h}$. After calcination, the powder was ball-milled first for $2 \mathrm{~h}$ using $\mathrm{ZrO}_{2}$ balls with a diameter of $15 \mathrm{~mm}$, and then for additional $48 \mathrm{~h}$ using $\mathrm{ZrO}_{2}$ balls with a diameter of $2 \mathrm{~mm}$. The obtained material was single-phase $\mathrm{SrTiO}_{3}$ as confirmed by XRD. The grains were equiaxed in shape with an average size of approximately $0.2 \mu \mathrm{m}$.

\subsection{Preparation of sintered specimens}

Powder mixtures containing the matrix and template powders were mixed with a solvent ( $60 \mathrm{vol} \%$ toluene, $40 \mathrm{vol} \%$ ethanol), a binder [poly(vinyl butyral)], and a plasticizer (di-n-butyl phthalate), and were tape-cast to form sheets in which the template grains were aligned with their plate faces parallel to the sheet surface. The amount of $\mathrm{S}_{0.5} \mathrm{BT}$ template grains in the specimens was $0,1,5$, or $10 \mathrm{vol} \%$, and this amount is indicated in parentheses following the abbreviation of the specimen's name, e.g., $\operatorname{BiT}(5 \%)$. The sheets were cut into pieces with a size of $30 \mathrm{~mm} \times 30 \mathrm{~mm}$, and the pieces were laminated and pressed in a die at $80^{\circ} \mathrm{C}$ and $50 \mathrm{MPa}$ for $3 \mathrm{~min}$ to form green compacts with a thickness of approximately $2 \mathrm{~mm}$. The compacts were further cut into small pieces $(10 \mathrm{~mm} \times 10 \mathrm{~mm})$. The binder in the compacts was burnt out by heating at $500^{\circ} \mathrm{C}$ for $2 \mathrm{~h}$, and then the compacts were sintered at various temperatures for $2 \mathrm{~h}$ in air (the heating rate was $100^{\circ} \mathrm{C} / \mathrm{h}$ ).

In addition to the textured ceramics, specimens with a random orientation were prepared. The $\mathrm{BiT}$ and $\mathrm{SrTiO}_{3}$ powders were mixed in deionized water for $1 \mathrm{~h}$ using a magnetic stirrer. The amount of $\mathrm{SrTiO}_{3}$ used in these specimens was the same as that of textured ceramics. The mixtures were uniaxially pressed at 5.7 MPa into disks with a diameter of $11 \mathrm{~mm}$ in diameter and thickness of $4 \mathrm{~mm}$, and then isostatically pressed at $98 \mathrm{MPa}$ to prevent preferred orientation of $\mathrm{BiT}$ grains with an aspect ratio other than 1 . The compacts were sintered at $1150^{\circ} \mathrm{C}$ for $2 \mathrm{~h}$ in air. These specimens are represented as BiTST- $x ; x$ indicates the $\mathrm{SrTiO}_{3}$ concentration in BiTST.

\subsection{Characterization}

The crystalline phases and the degree of orientation were evaluated by XRD (D8 ADVANCE, Bruker AXS, Karlsruhe, Germany) using $\mathrm{Cu} \mathrm{K} \alpha$ radiation on the major surface (the same as the sheet surface) of the sintered specimens.

The degree of orientation was evaluated by the Lotgering $\mathrm{F}$ value using the diffraction lines between $2 \theta=10$ and $60^{\circ}$; $\mathrm{F}=1$ and 0 indicate that the compacts are perfectly textured and randomly oriented, respectively. ${ }^{13)}$ The microstructure was observed with a field-emission scanning electron microscope
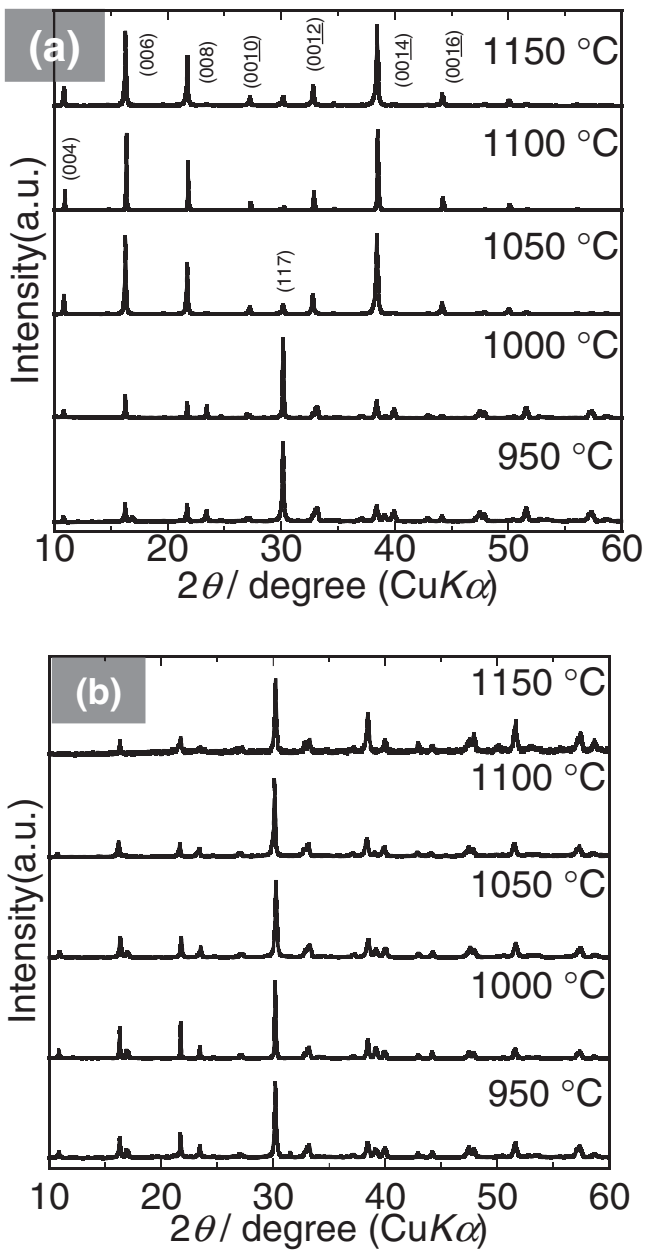

Fig. 2. XRD patterns of (a) $\operatorname{BiT}(5 \%)$ and (b) $\mathrm{BiT}(10 \%)$ sintered at various temperatures for $2 \mathrm{~h}$.

(Model S-4700, Hitachi, Tokyo, Japan); the fractured and thermally etched sections perpendicular to the major surface were observed. For some specimens, the surfaces were polished and thermally etched. One microstructure shown in Fig. 5(d) was observed on the major surface of the as-sintered specimen. The density was measured by the Archimedes method using water as the immersion medium and the relative density was calculated from the theoretical densities of $\mathrm{BiT}$ and $\mathrm{S}_{0.5} \mathrm{BT}$, assuming that no chemical reaction had occurred. The theoretical density of BiT and $\mathrm{S}_{0.5} \mathrm{BT}$ was 8.045 and $7.680 \mathrm{~g} / \mathrm{cm}^{3}$, respectively. ${ }^{14), 15)}$

\section{Results and discussion}

Figure 2 shows the XRD patterns of $\operatorname{BiT}(5 \%)$ and $\operatorname{BiT}(10 \%)$ sintered at various temperatures for $2 \mathrm{~h}$. For $\operatorname{BiT}(5 \%)$, the most intense peak was $(117)$ up to $1000^{\circ} \mathrm{C}$. The relative intensity of the $(00 l)$ lines increased at $1050^{\circ} \mathrm{C}$ and no significant change was further observed in the specimens sintered at higher temperatures. The intense $(00 l)$ lines indicate the development of $\langle 001\rangle$ texture in the specimens sintered at and above $1050^{\circ} \mathrm{C}$. For $\operatorname{BiT}(1 \%)$, whose diffraction patterns are not shown here, the diffraction patterns were almost the same as those of $\mathrm{BiT}(5 \%)$ with a minor difference in the relative intensity between $(00 l)$ and (117). On the other hand, for $\operatorname{BiT}(10 \%)$, the most intense peak was (117) at all temperatures up to $1150^{\circ} \mathrm{C}$, the highest temperature in this experiment, and an increase in the relative intensity of $(00 l)$ was hardly observed. 


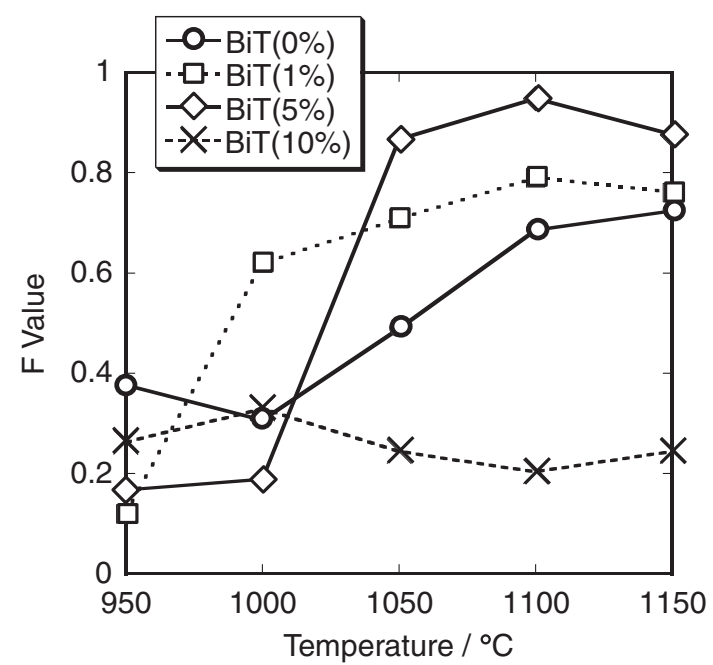

Fig. 3. Effect of sintering temperature on texture development in BiT containing various amount of $\mathrm{Sr}_{0.5} \mathrm{BT}$ template sintered for $2 \mathrm{~h}$.

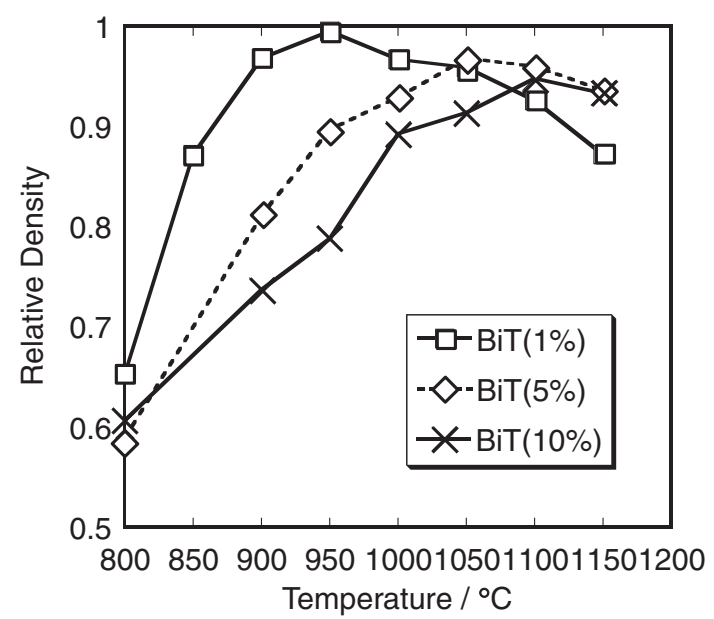

Fig. 4. Effect of sintering temperature on densification.
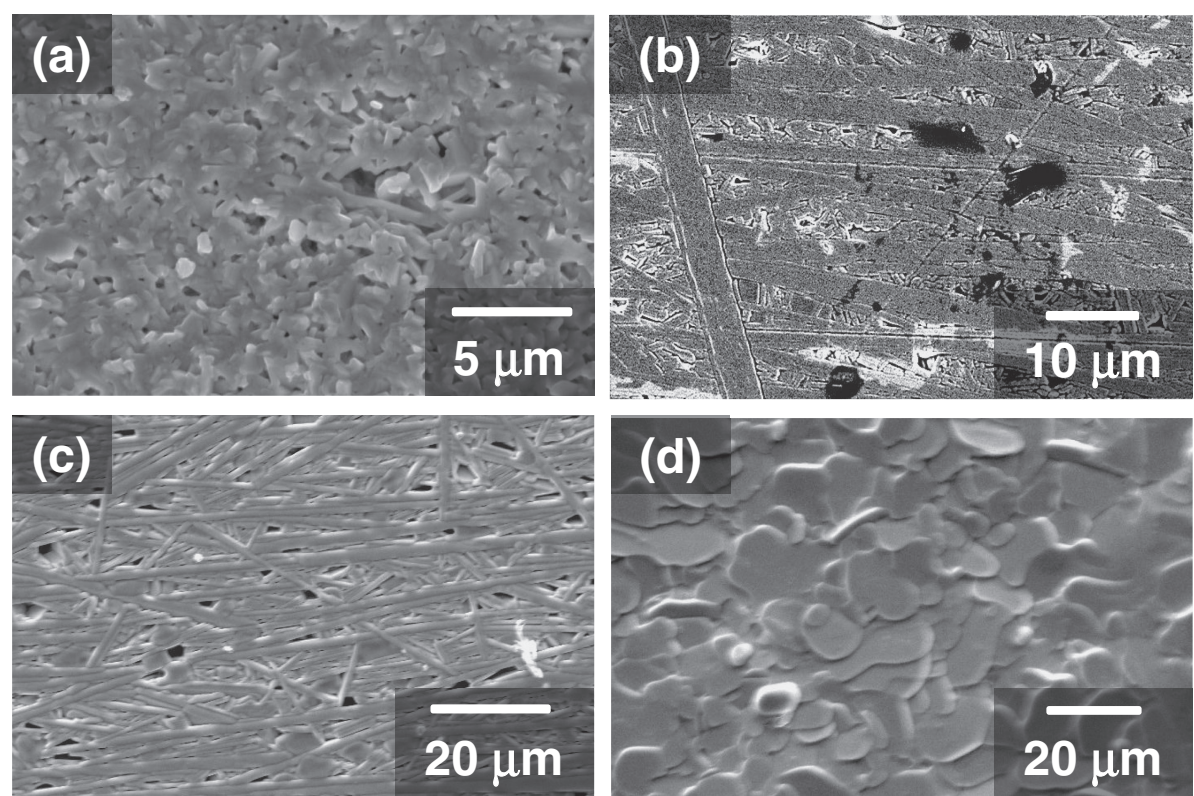

Fig. 5. Microstructures of $\operatorname{BiT}\left(5 \%\right.$ ) sintered at (a) $1000^{\circ} \mathrm{C}$, (b) $1050^{\circ} \mathrm{C}$, (c) $1100^{\circ} \mathrm{C}$, and (d) $1150^{\circ} \mathrm{C}$ for $2 \mathrm{~h}$. Figure (d) shows the observation on the major surface of the as-sintered specimen.

Figure 3 shows the effect of sintering temperature on the $\mathrm{F}$ value. The result for $\mathrm{BiT}(0 \%)$ is also shown for comparison. The F value of all specimens except BiT(10\%) increased with an increase in the sintering temperature. The onset of texture development was between 950 and $1000^{\circ} \mathrm{C}$ for $\mathrm{BiT}(1 \%)$ and between 1000 and $1050^{\circ} \mathrm{C}$ for $\operatorname{BiT}(5 \%)$. The maximum $\mathrm{F}$ value for $\operatorname{BiT}(5 \%)$ was higher than that for $\operatorname{BiT}(1 \%)$. On the other hand, for $\mathrm{BiT}(10 \%)$, the $\mathrm{F}$ value remained low irrespective of the sintering temperature, and the value at $1150^{\circ} \mathrm{C}$ was less than 0.3 . In textured ceramics made by the TGG process, the degree of orientation increases with the concentration of template grains. ${ }^{16)}$ Therefore, the low $\mathrm{F}$ value in $\mathrm{BiT}(10 \%)$ is unusual.

One of the mechanisms of the texture development is the growth of template grains. ${ }^{3), 4)}$ In general, a high relative density of above $90 \%$ is required for grain boundary migration, ${ }^{17)}$ and rigid inclusion grains inhibit densification. ${ }^{18)}$ It is possible that the low $\mathrm{F}$ value in $\mathrm{BiT}(10 \%)$ is caused by the hindrance to densification by template grains. To examine this possibility, the densification behavior was examined (Fig. 4). The densification curve shifted toward high temperatures with an increase in the concentration of template grains. For BiT(10\%), however, the relative density reached approximately $90 \%$ at $1000^{\circ} \mathrm{C}$. Therefore, it is highly unlikely that the hindrance to densification by the template grains leads to the low $\mathrm{F}$ value for $\mathrm{BiT}(10 \%)$ at $1150^{\circ} \mathrm{C}$.

To examine the origin of texture development in $\operatorname{BiT}(1 \%)$ and $\operatorname{BiT}(5 \%)$ and the low $\mathrm{F}$ value for $\operatorname{BiT}(10 \%)$, the microstructure development was investigated. First, the microstructures of $\operatorname{BiT}(5 \%)$ with the highest $\mathrm{F}$ value is shown. Figure 5 shows the microstructures of $\operatorname{BiT}(5 \%)$ sintered at various temperatures for $2 \mathrm{~h}$; Figs. 5(a)-5(c) are side views and Fig. 5(d) is a top view of the specimens with a square plate shape. The observation from the top and side faces of the specimen indicated that the grains had a circular plate shape. No significant change was observed in the specimen sintered at $1000^{\circ} \mathrm{C}$. In the microstructure at $1050^{\circ} \mathrm{C}$, 
some grains grew to large grains elongated along the axial direction. The thickness was also increased. These grains can be discriminated from short thin grains, and will be called large platelike grains hereafter.

Large platelike grains grew at $1050^{\circ} \mathrm{C}$, and the grain size distribution became bimodal. Majority of the large platelike grains were aligned with their plate face parallel to the sheet surface, and a small amount of randomly oriented grains were also observed. There were groups of small grains between the large platelike grains. These small grains were platelike in shape. Few of the small platelike grains were aligned with their plate faces parallel to that of large platelike grains but many of them were misoriented. In the specimen sintered at $1100^{\circ} \mathrm{C}$, the size of both the large and small platelike grains increased. The growth of the large platelike grains at the expense of small platelike grains and the growth of small platelike grains within the groups of small grains resulted in an increase in the degree of orientation. The fact that the number of the large platelike grains on the top surface was small [Fig. 5(d)] suggested that the large platelike grains grew mainly in the inner part of the compacts.

The origin of texture development in $\mathrm{BiT}(5 \%)$ can be explained from these observations. The main change up to $1000^{\circ} \mathrm{C}$ is densification, and no significant change in the microstructure is occurred. Grain growth and change in the aspect ratio occur between 1000 and $1050^{\circ} \mathrm{C}$; the template grains grow and the degree of orientation increases. The small grains in the group of grains between the large platelike grains also grow and develop a platelike shape. Because the orientation of the growing small grains is restricted by the large platelike grains, there is an increase in the amount of grains having an orientation identical to the large platelike grains, thus contributing to an increase in the degree of orientation.

Figure 6 shows the microstructures of $\operatorname{BiT}(1 \%)$ sintered at various temperatures for $2 \mathrm{~h}$. No significant change in the microstructure was observed in the specimen sintered at $950^{\circ} \mathrm{C}$. Large platelike grains were formed at $1000^{\circ} \mathrm{C}$, and both large and small platelike grains grew at $1100^{\circ} \mathrm{C}$. These characteristics are similar to those of $\operatorname{BiT}(5 \%)$, but there are some differences. First, the lowest temperature at which the large platelike grains is formed is $1000^{\circ} \mathrm{C}$ for $\mathrm{BiT}(1 \%)$, whereas that is $1050^{\circ} \mathrm{C}$ for $\mathrm{BiT}(5 \%)$. This difference can be explained by the densification behavior (Fig. 4). The densification rate is reduced by the addition of template grains, ${ }^{18)}$ and thus, the temperature at which extensive grain boundary migration can be possible is higher for $\mathrm{BiT}(5 \%)$ than for $\operatorname{BiT}(1 \%)$.

The second difference is the number density of the large platelike grains. The large platelike grains are formed from the template grains. Therefore, the number density of the large platelike grains for $\mathrm{BiT}(5 \%)$ is expected to be higher than that for $\operatorname{BiT}(1 \%)$. However, we found that the large platelike grains could also be formed without the template grains. Figure 7 shows the microstructures of $\operatorname{BiT}(0 \%)$ sintered at various temperatures for $2 \mathrm{~h}$; $\operatorname{BiT}(0 \%)$ had no template grains and was prepared by the same procedure as that used for $\operatorname{BiT}(1 \%)$ and $\operatorname{BiT}(5 \%)$. The grains developed a platelike shape at $1000^{\circ} \mathrm{C}$, but large platelike grains were not formed. Large platelike grains were formed at $1050^{\circ} \mathrm{C}$, and the size and the number density of the large platelike grains increased with an increase in the sintering temperature. The $\mathrm{F}$ value for $\mathrm{BiT}(0 \%)$ sintered at 1100 and $1150^{\circ} \mathrm{C}$ was approximately 0.6 (Fig. 3). The possible mechanism of the development of texture in $\operatorname{BiT}(0 \%)$ with $\mathrm{F}$ values of approximately 0.6 in the absence of template grains can be explained as follows. The matrix BiT grains were not perfectly equiaxed but
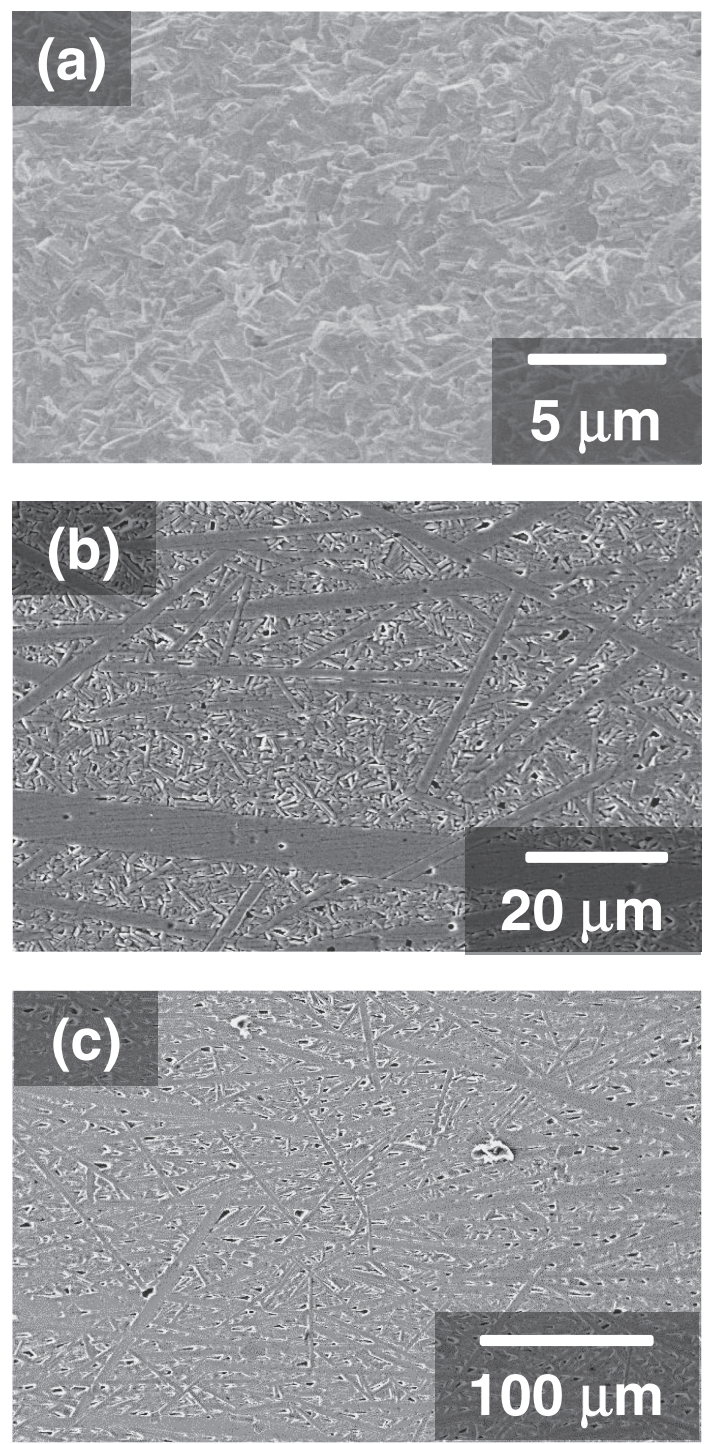

Fig. 6. Microstructures of $\operatorname{BiT}(1 \%)$ sintered at (a) $950^{\circ} \mathrm{C}$, (b) $1000^{\circ} \mathrm{C}$, and (c) $1100^{\circ} \mathrm{C}$ for $2 \mathrm{~h}$.

platelike to some extent. Some matrix grains with relatively high aspect ratios were aligned by tape-casting and grew to large platelike grains at temperatures more than $1050^{\circ} \mathrm{C}$. Because of the distribution of the aspect ratios, the amount of grains growing to large platelike grains increased with an increase in the sintering temperature. Because the matrix grains did not have aspect ratios high enough for grain orientation in the green compacts, the degree of orientation of the matrix grains was rather small, resulting in an $\mathrm{F}$ value of approximately 0.6 in the sintered compacts. In $\mathrm{BiT}(1 \%)$, the matrix grains possibly grew to large platelike grains. Therefore, the amount of large platelike grains was more than that expected from the amount of template grains.

Third difference is the difference in the amount of misoriented, large platelike grains in $\mathrm{BiT}(1 \%)$ and $\mathrm{BiT}(5 \%)$. In $\mathrm{BiT}(5 \%)$, almost all large platelike grains are aligned with their plate face parallel to the sheet surface, indicating that the large platelike grains grow from the template grains. On the other hand, in BiT(1\%), a large amount of misoriented, large platelike grains are present, indicating that the large platelike grains are derived from matrix grains as well as template grains. A large amount of misoriented large platelike grains is responsible for the maximum $\mathrm{F}$ value of $\operatorname{BiT}(1 \%)$ less than that of $\operatorname{BiT}(5 \%)$. 

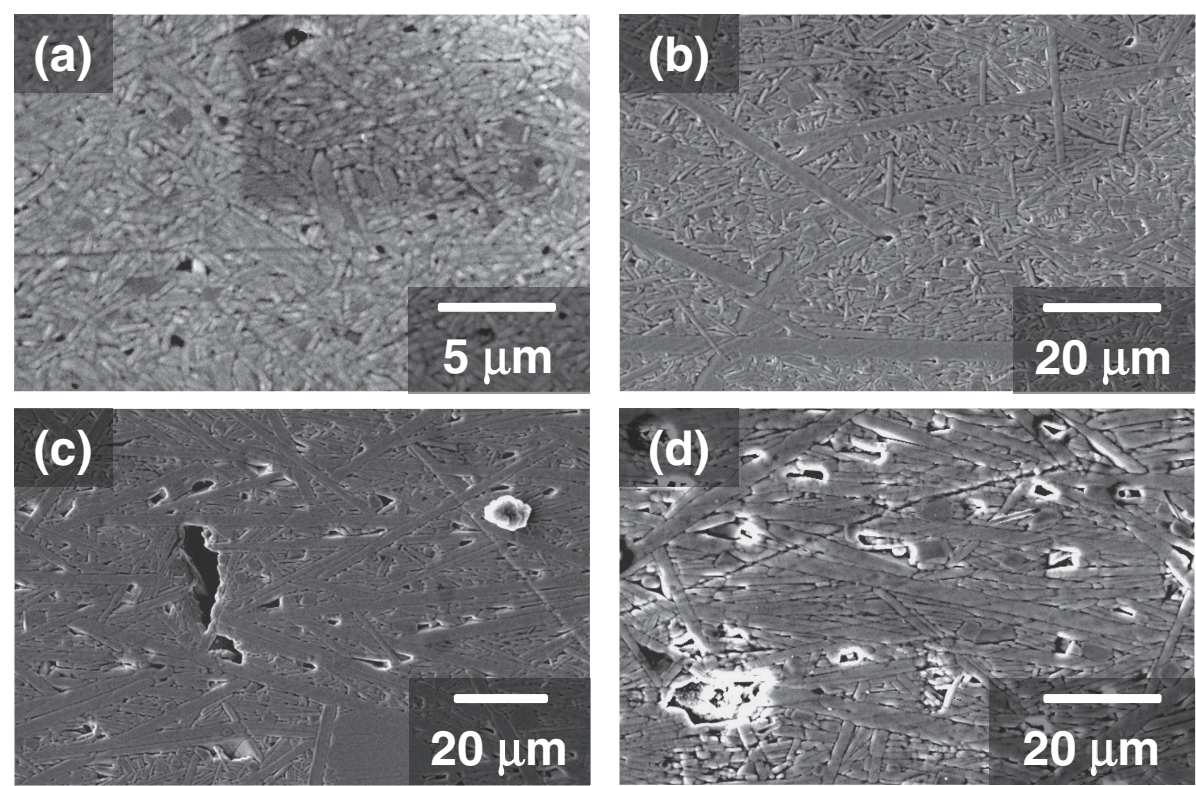

Fig. 7. Microstructures of $\operatorname{BiT}(0 \%)$ sintered at (a) $1000^{\circ} \mathrm{C}$, (b) $1050^{\circ} \mathrm{C}$, (c) $1100^{\circ} \mathrm{C}$, and (d) $1150^{\circ} \mathrm{C}$ for $2 \mathrm{~h}$.

Figure 8 shows the microstructures of $\operatorname{BiT}(10 \%)$ sintered at various temperatures for $2 \mathrm{~h}$. Large platelike grains did not form up to $1150^{\circ} \mathrm{C}$, which was the maximum sintering temperature in this experiment, and the only change in the microstructure was the change in the grain shape to platelike. The hindrance to rapid grain growth of template and matrix grains is responsible for a low $\mathrm{F}$ value.

A comparison of microstructure development in $\operatorname{BiT}(5 \%)$ and BiT(10\%) indicates that the addition of a large amount of template grains reduces the grain boundary migration rate. In the present experiment, the template grains have the composition different from that of the matrix grains, and $\mathrm{BiT}(10 \%)$ contains a high concentration of $\mathrm{SrTiO}_{3}$ than $\mathrm{BiT}(5 \%)$. Therefore, the possibility of dissolution of $\mathrm{SrTiO}_{3}$ in $\mathrm{BiT}$ was examined. Figure 9 shows the XRD patterns of $\mathrm{BiT}(10 \%)$ sintered at 950 and $1150^{\circ} \mathrm{C}$ and $\mathrm{BiT}(20 \%)$ sintered at $1150^{\circ} \mathrm{C}$. The diffraction lines (007) and (0016) of $\mathrm{S}_{0.5} \mathrm{BT}$ were confirmed for $\mathrm{BiT}(10 \%)$ sintered at $950^{\circ} \mathrm{C}$ and $\mathrm{BiT}(20 \%)$ sintered at $1150^{\circ} \mathrm{C}$. The absence of these lines in $\mathrm{BiT}(10 \%)$ sintered at $1150^{\circ} \mathrm{C}$ indicates that approximately $10 \% \mathrm{~S}_{0.5} \mathrm{BT}$ dissolve in BiT. Figure 10 shows the XRD profiles of (2014) and (0214) of BiT in BiTST- $x$ with different $\mathrm{SrTiO}_{3}$ concentrations sintered at $1150^{\circ} \mathrm{C}$ for $2 \mathrm{~h}$. Two diffraction lines were separated in BiTST-1, but they broadened and overlapped each other with an increase in the $\mathrm{SrTiO}_{3}$ concentration. The diffraction angles shifted toward low angles, indicating an increase in the lattice parameters. The crystal structures of $\mathrm{BiT}, \mathrm{S}_{0.5} \mathrm{BT}$, and $\mathrm{SrBi}_{4} \mathrm{Ti}_{4} \mathrm{O}_{15}$ (SBT) suggest that $\mathrm{SrTiO}_{3}$ enters in pseudo-perovskite units and increases the lattice parameter of the $c$-axis. ${ }^{19}$ )

Because the presence of template grains influences the growth behavior of the matrix grains, the grain growth in the BiTST- $x$ system, which did not contain template grains, was examined. Figure 11 shows the microstructures of BiTST- $x$ sintered at $1150^{\circ} \mathrm{C}$ for $2 \mathrm{~h}$. The specimens with $x=1$ and 5 were composed of large platelike grains. The grain size reduced as the $\mathrm{SrTiO}_{3}$ concentration was increased to $5 \%$. Extensive grain growth was not observed in BiTST-10. This result indicates that the dissolution of $\mathrm{SrTiO}_{3}$ in $\mathrm{BiT}$ reduces the grain boundary migration rate.
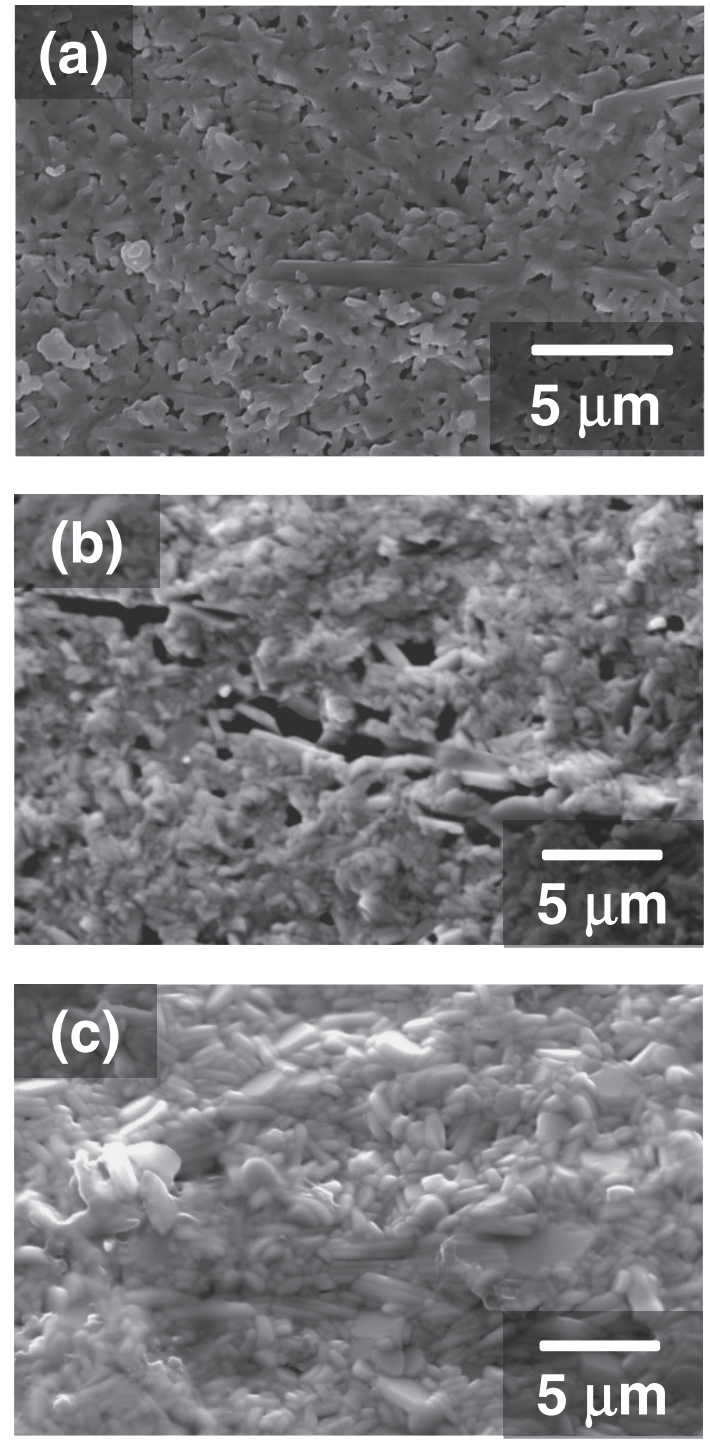

Fig. 8. Microstructures of $\operatorname{BiT}(10 \%)$ sintered at (a) $1000^{\circ} \mathrm{C}$, (b) $1100^{\circ} \mathrm{C}$, and (c) $1150^{\circ} \mathrm{C}$ for $2 \mathrm{~h}$. 

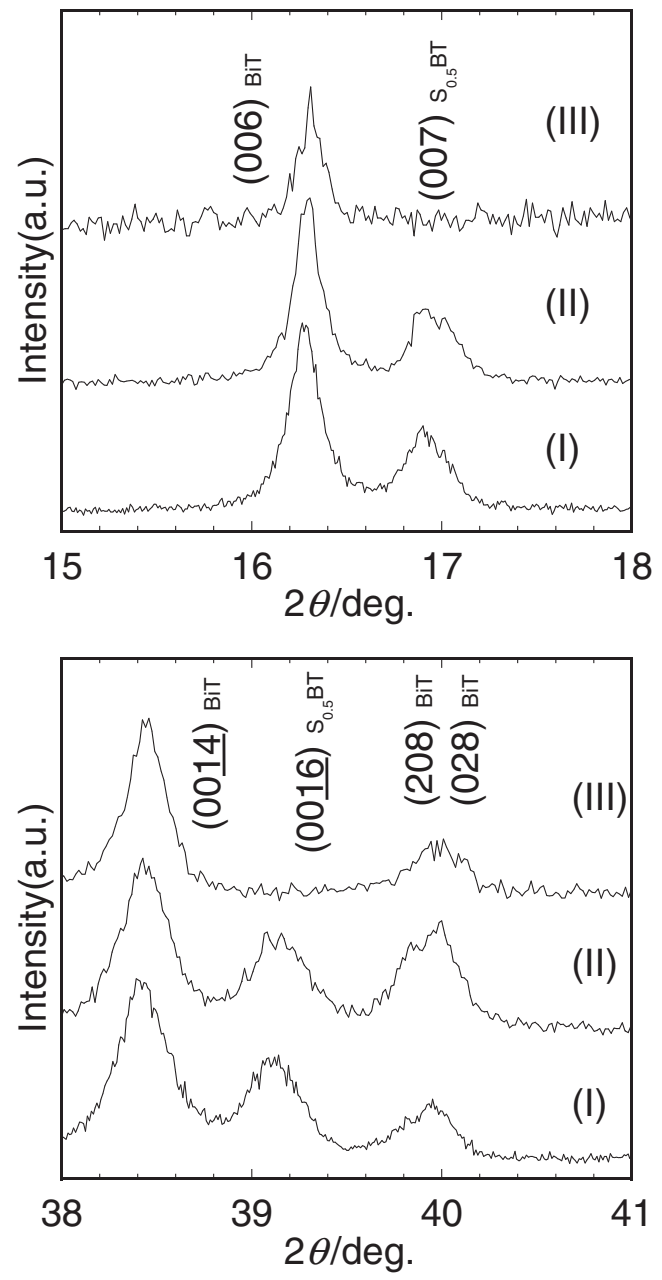

Fig. 9. XRD patterns of (I) $\mathrm{BiT}(20 \%)$ sintered at $1150^{\circ} \mathrm{C}$, (II) $\operatorname{BiT}(10 \%)$ at $950^{\circ} \mathrm{C}$, and (III) $\operatorname{BiT}(10 \%)$ at $1150^{\circ} \mathrm{C}$ for $2 \mathrm{~h}$.

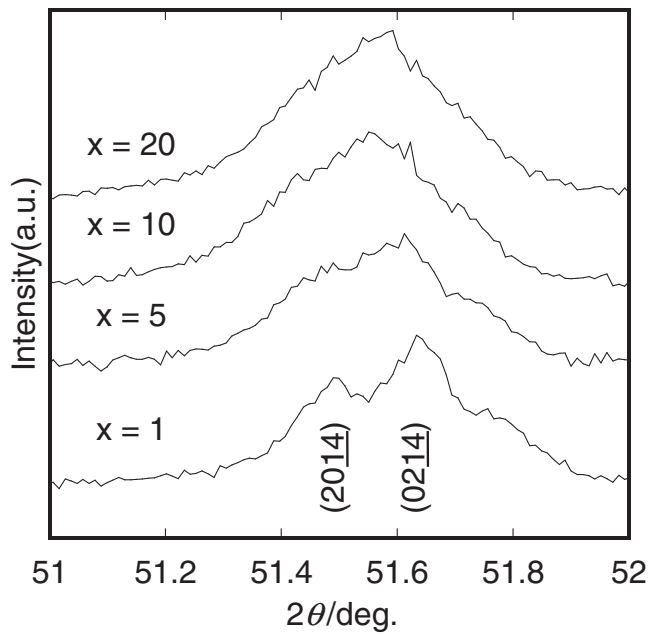

Fig. 10. XRD patterns of BiTST- $x$ sintered at $1150^{\circ} \mathrm{C}$ for $2 \mathrm{~h}$.

It is expected that the template grains with a composition different from that of matrix grains do not grow. In the present case, however, $\mathrm{SrTiO}_{3}$ in the $\mathrm{S}_{0.5} \mathrm{BT}$ template grains dissolved in the matrix $\mathrm{BiT}$ grains, and the template grain as well as the matrix grains changed to $\mathrm{SrTiO}_{3}$-doped $\mathrm{BiT}$. This is supported by the disappearance of diffraction lines at $2 \theta=16.9$ and $39.1^{\circ}$ [(007)
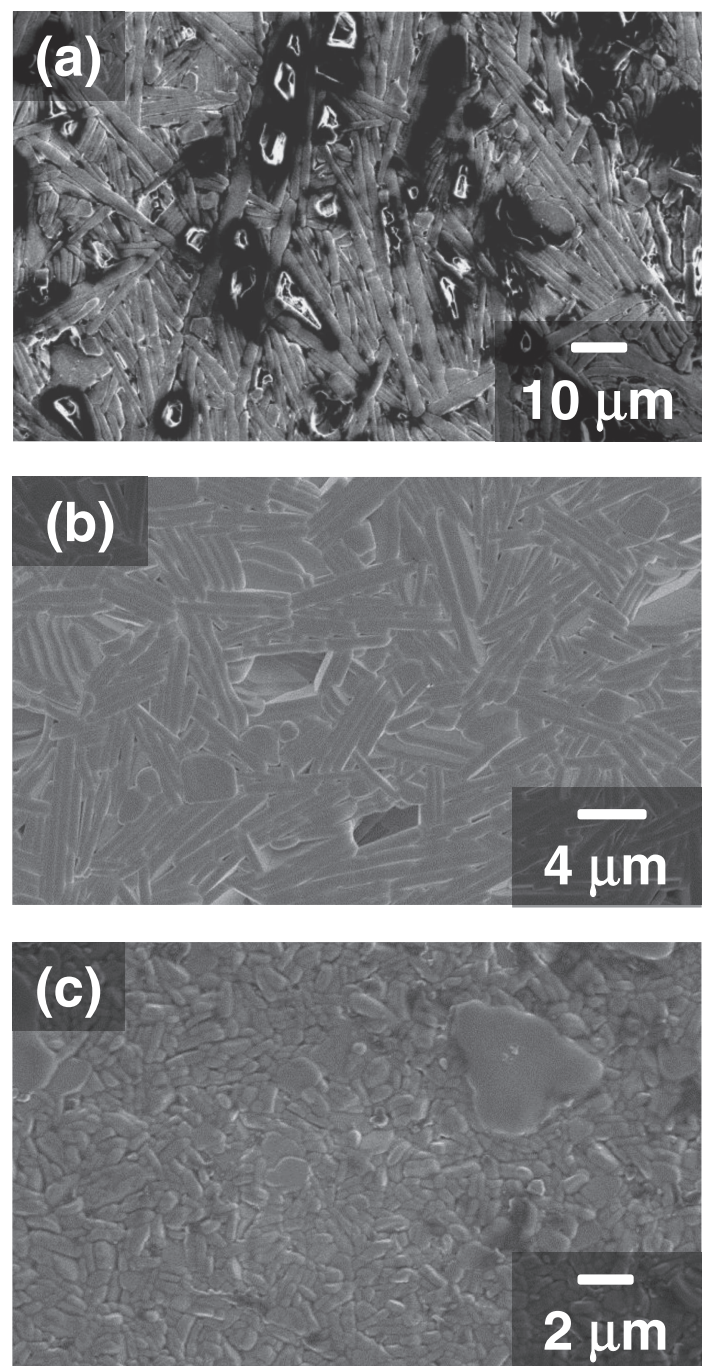

Fig. 11. Microstructures of BiTST- $x$ (a) $x=1$, (b) $x=5$, and (c) $x=10$ sintered at $1150^{\circ} \mathrm{C}$ for $2 \mathrm{~h}$.

and (0016) of $\mathrm{Sr}_{0.5} \mathrm{BT}$, respectively] between 1000 and $1050^{\circ} \mathrm{C}$ in BiT(5\%) shown in Fig. 2(a). Because the template and matrix grains had the same crystal structure, the template grains were able to grow at the expense of the matrix grains. Thus, it is judged that the $\mathrm{S}_{0.5} \mathrm{BT}$ template grains are the origin of the large platelike grains with their plate face parallel to the major surface of the $\operatorname{BiT}(1 \%)$ and $\operatorname{BiT}(5 \%)$ specimens.

In general, three mechanisms are possible for the reduction in the grain boundary migration rate by the additives with the composition different from that of the matrix phase; solute-drag, ${ }^{20}$ ) pinning by second-phase grains, ${ }^{21)}$ and change in grain boundary structure at an atomic level. ${ }^{22}$ In the present case, the pining by second-phase grains is ruled out because the diffraction lines of $\mathrm{S}_{0.5} \mathrm{BT}$ were not observed in the specimen sintered at $1150^{\circ} \mathrm{C}$ for $2 \mathrm{~h}$ (Fig. 9). Furthermore, although the concentration of $\mathrm{S}_{0.5} \mathrm{BT}$ is $10 \mathrm{vol} \%$, the number density of $\mathrm{S}_{0.5} \mathrm{BT}$ is very small, and almost all parts of the matrix phase are $\mathrm{BiT}$ without $\mathrm{S}_{0.5} \mathrm{BT}$ grains.

The grain boundary structure at an atomic level determines the grain growth rate. A typical example of this effect has been reported for $\mathrm{BaTiO}_{3}{ }^{22)}$ When the boundary structure is atomically rough and smooth, the grain boundaries can migrate under a low and high driving force, respectively. This effect is also observed in BLSFs. The grain growth in BiT is extensive, as 

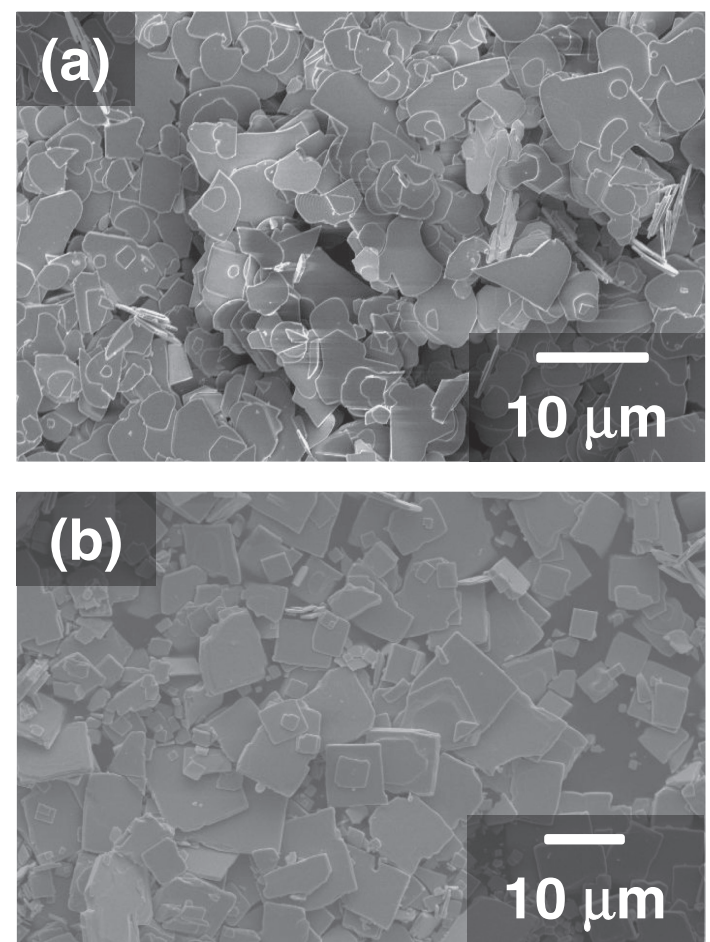

Fig. 12. Shape and size of (a) $\mathrm{SrTiO}_{3}$-doped BiT and (b) $\mathrm{SrBi}_{4} \mathrm{Ti}_{4} \mathrm{O}_{15}$ platelike grains made by molten salt synthesis.

shown in Fig. 7, whereas the growth is limited in $\mathrm{BaBi}_{4} \mathrm{Ti}_{4} \mathrm{O}_{15}$ (BBT). ${ }^{10)}$ When the platelike grains are prepared by molten salt synthesis, circular plates, similar to those shown in Fig. 1, are obtained for BiT, whereas square plates are obtained for BBT. These grain shapes indicate that the side faces parallel to the $c$-axis are atomically rough and smooth for $\mathrm{BiT}$ and $\mathrm{BBT}$, respectively. ${ }^{23)}$ The platelike grains of $\mathrm{SrBi}_{4} \mathrm{Ti}_{4} \mathrm{O}_{15}$ (SBT) and BiT doped with $\mathrm{SrTiO}_{3}$ were prepared by molten salt synthesis; the $\mathrm{SrTiO}_{3}$ concentration in $\mathrm{SrTiO}_{3}$-doped $\mathrm{BiT}$ is the same as that in BiT(10\%). Figure 12 shows the SEM photographs of the resultant powders. The $\mathrm{SBT}$ and $\mathrm{SrTiO}_{3}$-doped $\mathrm{BiT}$ grains had shapes of square and circular plates, respectively. This result indicates that the boundary structure of $\mathrm{BiT}(10 \%)$ is atomically rough, and the boundary structure does not change by the dissolution of $\mathrm{SrTiO}_{3}$ in $\mathrm{BiT}$.

The elimination of the possibilities of pinning by second-phase grains and the change in the boundary structure suggest that the origin of the reduction in boundary migration rate is solute-drag. In $\mathrm{BiT}(1 \%)$ and $\mathrm{BiT}(5 \%)$, the concentration of $\mathrm{SrTiO}_{3}$ in $\mathrm{BiT}$ is not sufficiently high to suppress grain growth to a great extent, but an increase in the $\mathrm{SrTiO}_{3}$ concentration reduced the grain growth rate. In this case, the growth of template grains and also the growth of matrix grains assisted by the presence of template grains result in a high degree of orientation, as in the case of $\mathrm{BiT}(1 \%)$ and $\mathrm{BiT}(5 \%)$. When the concentration of $\mathrm{SrTiO}_{3}$ is increased as in $\operatorname{BiT}(10 \%)$, the grain boundaries can only migrate under a high driving force. In this case, texture does not form. In other words, the growth of template and matrix grains is the origin of texture development in BiT.

\section{Conclusion}

The texture development of BiT made by the TGG process was examined using $\mathrm{S}_{0.5} \mathrm{BT}$ hetero-templates with various concentrations. When the concentration was 1 and 5 vol \%, the micro- structures were composed of platelike grains with a bimodal size distribution. The formation of large platelike grains was the major origin of texture development, but small platelike grains between the large platelike grains also contributed to the degree of orientation. Almost all the large platelike grains were originated from template grains in $\mathrm{BiT}(5 \%)$, but the matrix grains with relatively high aspect ratios (approximately 3 ) also acted as the origin of the large platelike grains in $\operatorname{BiT}(1 \%)$. The degree of orientation of the matrix grains in the green compact was low as compared to that of template grains, resulting in a low degree of orientation in $\operatorname{BiT}(1 \%)$.

$\mathrm{SrTiO}_{3}$ in $\mathrm{S}_{0.5} \mathrm{BT}$ dissolved in the BiT matrix grains and reduced the grain boundary migration rate, probably by solutedrag. In $\operatorname{BiT}(5 \%)$, this effect was not so significant, and textured ceramics with an $\mathrm{F}$ value of approximately 0.9 were obtained. In $\operatorname{BiT}(10 \%)$, on the other hand, the effect was significant and no large platelike grains were formed and the $\mathrm{F}$ value remained low. In other words, extensive grain growth is necessary for texture development in BiT.

\section{References}

1) T. Takenaka, H. Nagata and Y. Hiruma, Jpn. J. Appl. Phys., 47, 3787-3801 (2008).

2) T. Takenaka, J. Ceram. Soc. Japan, 110, 215-224 (2002).

3) G. L. Messing, S. Trolier-McKinstry, E. M. Sabolsky, C. Duran, S. Kwon, B. Brahmaroutu, P. Park, H. Yilmaz, P. W. Rehrig, K. B. Eitel, E. Suvaci, M. Seabaugh and K. S. Oh, Crit. Rev. Solid State Mater. Sci., 29, 45-96 (2004).

4) T. Kimura, J. Ceram. Soc. Japan, 114, 15-25 (2006).

5) C. A. Randall, N. Kim, J.-P. Kucera, W. Cao and T. R. Shrout, J. Am. Ceram. Soc., 81, 677-688 (1998).

6) H. Takahashi, Y. Numamoto, J. Tani and S. Tsurekawa, Jpn. J. Appl. Phys., 45, 7405-7408 (2006).

7) M. N. Rahaman, "Ceramic Processing and Sintering", 2nd ed., Marcel Dekker, New York (2003) pp. 693-702.

8) J. Horn, S. C. Zhang, G. L. Messing and S. Trolier-McKinstry, J. Am. Ceram. Soc., 82, 921-926 (1999).

9) Y. Sakuma and T. Kimura, J. Electroceram., 13, 537-541 (2004).

10) T. Kimura and Y. Yoshida, J. Am. Ceram. Soc., 89, 869-874 (2006).

11) T. Kimura, Y. Sakuma and M. Murata, J. Eur. Ceram. Soc., 25, 2227-2230 (2005).

12) T. Kimura and C. Miyazaki, J. Electroceram., 19, 281-285 (2007).

13) F. K. Lotgering, J. Inorg. Nucl. Chem., 9, 113-123 (1959).

14) Powder Diffraction File, 35-795, International Centre for Diffraction Data, Swarthmore, Pa, U.S.A. (1990).

15) Powder Diffraction File, 31-1342, International Centre for Diffraction Data, Swarthmore, Pa, U.S.A. (1988).

16) T. Kimura, T. Takahashi, T. Tani and Y. Saito, J. Am. Ceram. Soc., 87, 1424-1429 (2004).

17) M. N. Rahaman, "Ceramic Processing and Sintering", 2nd ed., Marcel Dekker, New York (2003) pp. 586-590.

18) M. N. Rahaman, "Ceramic Processing and Sintering", 2nd ed., Marcel Dekker, New York (2003) pp. 702-723.

19) T. Kikuchi, A. Watanabe and K. Uchida, Mater. Res. Bull., 3, 299-304 (1977).

20) M. N. Rahaman, "Ceramic Processing and Sintering", 2nd ed., Marcel Dekker, New York (2003) pp. 580-585.

21) M. N. Rahaman, "Ceramic Processing and Sintering", 2nd ed., Marcel Dekker, New York (2003) pp. 574-580.

22) S.-J. L. Kang, M.-G. Lee and S.-M. An, J. Am. Ceram. Soc., 92, 1464-1471 (2009).

23) T. Kimura and T. Tani, "Lead-Free Piezoelectric Ceramics", Ed. by S. Priya and S. Nahm, Springer, New York (2012) pp. $461-483$. 